\title{
Energy for sustainable rural development
}

\author{
W.S. Hulscher and E.W. Hommes
}

\begin{abstract}
Rural energy in developing countries is discussed with a view to sustainable development. The project-oriented approach in rural energy which has often dominated in the past, is contrasted with an overall strategy for sustainable rural energy demand and supply. An outline for a demand-oriented policy is formulated, indicating the role of the government in energy pricing and market development. Special attention is given to electricity as the fastest-growing energy subsector. It is concluded that major changes are required to accommodate and institutionalize the planning of decentralized energy supply.
\end{abstract}

Keywords: Sustainability; Energy; Rural development

The consumption of energy is very unevenly distributed in the world, and so is its growth. 'In the 1980s the consumption of commercial energy in Western Europe more or less stabilized at a relatively high level, whereas the USA combined substantial growth with a very high consumption level. In Asia, starting from a low consumption level, the increase was as high as two or three times the population growth. In South America the low per capita consumption slightly increased, but in Middle Africa the very low consumption hardly increased, which implied negative growth per capita. These global distinctions reflect large differences in development. policies and priorities.

Interest in energy planning developed after the first oil crisis, out of financial and political concerns. More recently the report of the Brundtland Committee ${ }^{2}$ put energy in the framework of sustainable development, which raised a lot of public attention. As a result, in many industrialized countries energy policies are now being seen in the perspective of global environmental sustainability.

The authors are with the Technology and Development Group, University of Twente, PO Box 217, 7500 AE Enschede, The Netherlands.
The drive to promote the rational use of energy gained new momentum. Efforts are now made to rationalize the consumption of electricity and to reduce the environmental effects of power production; public transport, the insulation of buildings and houses, retrofitting of boilers and improving the efficiency of industrial production processes are being promoted. Private cars are also becoming more efficient and less polluting. Research and development on environmentally sound energy technologies have become a priority. At the same time, the discussion on sustainable development has stimulated renewed interest in alternative sources such as wind and solar energy. Some of the policies still require a change in the attitudes and habits of the public. Especially discouraging is the fact that the use of private cars appears to be a major stumbling block.

In developing countries the situation is completely different. Biomass plays a major role as a noncommercial fuel in the residential sector and is widely used as a commercial fuel in other sectors, whereas the use of modern forms of energy is still limited. It is estimated that, by $1980,14 \%$ of global energy and $35 \%$ of energy used in developing countries was derived from biomass. ${ }^{3}$ National energy policies are often confined to fuel policies, and many developing countries have a stated objective of substituting imported fossil fuels by indigenous resources. Since 1980 the total amount of biofuel has increased, but biofuels have not been widely substituted for oil. ${ }^{4}$ At the same time, the expansion of the power sector and the economy at large is a common goal. Rational use of energy receives relatively little attention, and sustainability is not a major issue.

Electricity is a case in point. In some industrialized countries the delinking of energy and economic growth has led to an increase in electricity consumption, even when total energy consumption has decreased. ${ }^{5}$ In most developing countries, on the other hand, high growth figures in the electricity sector $^{6}$ are combined with low absolute levels of consumption, particularly in rural areas. The effects 
in both industrialized and developing countries are more or less the same as, worldwide, electricity is growing much faster than total commercial energy (in Europe almost four times as fast, and in South America twice as fast). ${ }^{7}$ Even in the stagnating economies of Middle Africa the power sector is keeping pace with the population increase.

The developing countries contribute less than one-quarter of world $\mathrm{CO}_{2}$ emissions from fuels ${ }^{8}$ and consume 10 to 20 times less energy per capita than industrialized countries, so they cannot be expected to take the lead in introducing measures to protect the global atmosphere, although they will be full partners in the international discussion on our common future. A different issue is raised by the local environmental effects of increasing energy consumption and production in the developing countries themselves. In this article we will focus on rural energy in the context of sustainable development and will discuss how to achieve sustainable rural energy policies.

\section{SUSTAINABILITY AND RURAL DEVELOPMENT}

In addition to the low absolute levels of energy consumption, there may be other reasons why the issues of sustainable energy use are less articulated in developing countries. First, their interest in the concept of sustainable development in general is much less than in the industrialized world. The need to survive and the wish to grow dominate the thinking of policy makers. Environmental problems are perceived as being created mainly by Western countries, which are also held responsible for solving them. Insofar as environmental problems are recognized in developing countries, local elites have a tendency to accept them as a price for development. Second, countervailing powers in the form of nongovernmental organizations have little democratic access to power. As a result the impact of NGOs on public discussions is limited. Third, technologies tend to follow their own dynamics. Modernization is largely based on technology push and supply orientation predominates over demand orientation.

In the last few decades, rural development has been promoted through increased agricultural production, small-scale industry, education and health. Infrastructure such as roads, irrigation and rural electrification were among the policy instruments. From the point of view of sustainable development many negative effects have been identified: land degradation, deforestation, desertification, and pollution by pesticides and fertilizers. The price for agricultural development has often been high. Though today sustainable rural development is the subject of many international discussions, there is still no consensus on the required strategies. The problem of combining low external input agriculture with the necessary increase in food production is difficult to solve.

In the rural economy agriculture and energy are closely intertwined. All agricultural systems not only consume, but also produce, energy. Perhaps twothirds of all rural energy in China comes from agricultural wastes. ${ }^{9}$ The conceptual unclarities of sustainable agriculture complicate the tasks of rural planners in developing countries who aim to develop a policy for energy planning in the framework of sustainable development. We will nevertheless try to formulate some guidelines.

\section{NATIONAL ENERGY PLANNING AND ENVIRONMENT}

In developing countries national energy planning is mainly based on a sectoral approach and is centred around fuel supplies. Consumption figures are extrapolated and little attention is given to the analysis of the nature of energy needs and demands. Priorities result from the allocation of scarce resources. Technical choices for energy conversions are based on the cheapest solution, and environmental considerations play a limited role. Due to effects of technology push, little attention has been given to energy rationalization and conservation. Few efforts have been made to meet decentralized demand in rural areas by alternative supplies. To the extent that decentralized sources of energy such as solar, wind and small hydropower, have been introduced in addition to biomass, this has generally been outside the mainstream of national energy planning. Here, too, environmental concerns have not been the main consideration.

From an environmental point of view, global and local interests do not always coincide, and can even conflict. Reduction of emissions from fossil fuels is a priority for the global environment. However, substitution by wood or hydroenergy can have serious adverse effects on local ecology. ${ }^{10}$ Moreover, developing countries cannot afford to substitute local coal by imported oil in order to protect the global atmosphere. The burning of agricultural waste in the fields is responsible for about $10 \%$ of all carbon released from biomass burning into the atmosphere. ${ }^{11}$ Of course this is undesirable from the global point of 
view but at the same time very necessary for local environmental management. Overall, poverty is not only an effect, but also a cause of degradation of the rural ecology. Escaping these vicious circles must have priority in the interests of the local and global environment.

On the energy consumption side, the options for environmental management are straightforward. Energy efficiency in the residential, transport and industrial sectors should be promoted. Unfortunately, many of the available options are not feasible for lack of finance and skills. As a result, energy planning for sustainable development is complicated. It is even more difficult to indicate which policy would meet the criteria for sustainable development.

Various authors have made suggestions for national energy planning in the framework of sustainable development. An interesting study is the demand-oriented approach which Johansson and Reddy applied to Sweden and Karnataka. ${ }^{12}$ They accept economic growth as a starting point but still aim to reduce $\mathrm{CO}_{2}$ emissions considerably. They show that it is possible to reach these goals by improving energy efficiency and by utilizing alternative sources such as biomass. This requires a revolutionary change in the approach to national energy planning.

In the Netherlands the objective of stabilizing or even reducing $\mathrm{CO}_{2}$ emissions ${ }^{13}$ can be reached by making fundamental improvements in energy efficiency (households can use one-quarter of the present energy consumption and still maintain the same level of comfort) ${ }^{14}$ and by much more intensive use of other sources such as wind and solar energy. Technically, many options are available, and under some conditions these options are cheaper than the conventional approach.

\section{TECHNOLOGIES FOR RURAL} ENERGY

Energy for rural societies has a number of specific characteristics which do not apply to urban areas. ${ }^{15}$ For instance, the demand for energy is scattered over a wide area and consists of relatively small requirements per consumption unit. Second, because of a lack of infrastructure, energy in the form of fossil fuels is not always available, or is available only at high cost. Third, renewable energy sources may, or may not, be locally available as part of the natural resources. In some areas the potential for renewables is great, in others it is slight and others are seriously affected by deficits. Fourth, various factors constrain the efficient use of energy, such as the low cash income of rural people, a lack of facilities and organizations, a lack of skills for maintaining equipment, and social and political structures that create very unbalanced access to fuels and hamper the effective use of existing energy sources.

Against the background of these characteristics, many rural development projects have included technologies for hydro, wind, biogas and solar energy. Most developing countries have experimented with these technologies in demonstration villages or pilot projects. Hydropower and even biogas have also been produced on a larger scale, and more recently projects using photovoltaics have been making an impact. So far the application of these technologies has not been motivated by concern for sustainable development; planners have opted for alternative technologies for reasons of socioeconomic development and decentralization. At the same time many demonstration villages have appeared to fail because the institutional bottlenecks were underestimated, or because the technologies were not as cheap and reliable as had been expected. ${ }^{16}$ However, one benefit of the pilot projects has been that development planners are now more familiar with the problems of implementing alternative technologies.

Similar conclusions can be drawn for social forestry projects insofar as they have been aimed at energy supply. Here as well we know much more now than we did 10 years ago, which allows us to take a step forward in planning and implementation. It has become clear that optimizing the use of technologies by carefully matching demand and supply is essential.

\section{TOWARDS A NEW POLICY}

As noted above, national energy planning is at present mainly supply oriented. Particularly in the power sector, it seems as if the major concern of planners is how to produce more electricity for the national grid. This leads automatically to large-scale production structures, mainly based on thermal power. At the same time, the fringes of the grid in rural areas are extremely uneconomic.

A completely different approach is to start with the systematic analysis of energy demand characteristics. In the courses on rural energy planning which we have developed at the University of Twente during the last decade ${ }^{17}$ matching demand and supply is one of the basic planning activities. In principle 
this is the same approach as that applied by Johansson and Reddy. However, theirs are national plans, although of course they have strong implications for rural areas.

Demand oriented planning for rural areas begins with energy demand surveys. The basic questions to be answered are of the type: for what, how much, where, when, in what form, and by whom is the energy needed, demanded and presently consumed? Such information is collected and specified per energy end-use activity, and then aggregated. It depends on the scope and context of any planned intervention which aggregation of the survey data will be appropriate. Relevant categories for aggregation can be consumer groups, (sub)sectors, regions, primary energy sources, time of day or year, and environmental impacts. The results from the energy demand surveys are then combined with data from an energy resource assessment and a systematic evaluation of technological options. This leads to an iterative process of matching energy demand and supply, aiming at satisfying the needs in an optimal way. Criteria for sustainability of the local environment predominate in the optimization. Of course the matching is a complicated activity, which requires a thorough understanding of site specific factors and the local environment. The type of interventions can, basically, be either supply oriented or demand oriented. The latter aim at the management of energy demand in such a way that energy needs can be satisfied with a minimal increase in the overall fuel supply in the region concerned.

Electricity provides a clear example. In rural areas electricity consumption is extremely low, and large areas have not yet been electrified. Decentralized supply is often a relevant option. Examples are diesel-generator sets, photovoltaic solar home systems, stand alone wind and hydro units and, for instance, combined heat and power generation by gasifiers. The important aspect of decentralized, small-scale electricity supply is that it calls for efficient use of the limited energy available. Already this criterion can be met by photovoltaics, which are greatly stimulating the market for energy-efficient appliances. Note that in some 40 years 'clean' solar energy will also be visible on the world energy supply map, which is not really very long compared to the lead time for power stations of about 25 years.

The varied energy demand in rural areas is best served by a mix of energy forms, with the corresponding technologies and sources. The choice between centralized and decentralized options is in the first place a matter of costs. Additional factors derive from technology assessment eg whether the technology can fit into the pattern of work and life of the users and operators. This is obvious in the case of energy utilization devices. Grid-connected electric rice cookers may be the preferred option for urban high-income groups, whereas a stand alone biogas system may be the more realistic option for a rural household. Under some conditions a mobile diesel pump is required by a farmer to irrigate his fields, whereas under other conditions a large-scale centrally powered water supply is feasible and more economical. In the case of energy supply technologies the choice does not depend in the first place on the end users, but rather on institutional aspects and conditions established by national governments.

\section{ROLE OF THE GOVERNMENT}

A crucial role is played by energy pricing, as discussed by Burgess. ${ }^{18}$ Energy pricing as part of government policy strongly influences the financial feasibility of the various technical options, and can direct energy supply to sustainable solutions. In many developing countries central grid electricity is highly subsidized. Following Kosmo it can be calculated that, for instance, in India the subsidy on central grid electricity amounts to some US $\$ 5$ billion annually. ${ }^{19}$ If such subsidies were reduced, decentralized options based on biomass, wind, small hydro or solar energy would become much more viable. If the same subsidy were given to the alternatives the electricity map would change drastically. A step further is to tax unsustainable production of electricity. The social (including environmental) costs per $\mathrm{kWh}$ are estimated to be about 12 US cents higher for conventional electricity than for photovoltaics. ${ }^{20}$ Sweden has already introduced a tax of roughly $300 \%$ on the use of fossil fuels. ${ }^{21}$ If social costs are incorporated into marketplaces, simple financial competitiveness would lead to a supply system completely different from what we have today.

The role of the market is strongly linked to the problem of energy pricing. Structural adjustments may be required. At present donor agencies tend to rely more on markets than on guided dissemination by government supported agencies. Among the reasons for this are managerial constraints in the developing countries. In rural areas improved stoves have often been distributed more effectively through the marketplace than through projects. Biogas, micro hydroturbines and solar equipment can all be distributed through the market.

Thus the market is a powerful mechanism, but why has it not yet worked properly? The first reason 
is the lack of proper energy pricing. It has simply not been attractive for individuals to buy the new devices. Second, many of the technologies on offer were not ready for the market. In fact, governmentsupported projects for renewable technologies were at the same time technical pilot projects. Third, some technologies, such as windmills, require training in their operation and maintenance, and the development of distribution systems for spare parts, which have often been neglected. Finally, many technologies need credit schemes, which have not been available. The lesson is that if we wish to rely more on the market, we must still take supporting measures.

Further support by governments for sustainable energy is required in the form of public campaigns and extension to particular rural groups for the promotion of rational energy use. The public reluctance in industrialized countries to move away from private cars may be indicative of the attitudinal changes required of farmers in developing countries if they are to adopt energy-efficient irrigation practices, or of households before they will adopt new cooking habits.

\section{INSTITUTIONAL DEVELOPMENT}

Shifting towards a new energy policy for rural areas requires some major institutional changes and, of course, proper policy decisions at the highest level. Many countries have developed special agencies for the promotion of renewables, sometimes within the ministry of energy, sometimes within the ministries of technology or rural development. Most of these agencies still occupy a weak position within the government structure..$^{22}$ Experience in the USA and Europe has taught that wind energy and solar energy develop only when they are accepted by the utility companies in combination with a favourable government policy. Only then do the alternatives enter the mainstream of energy planning.

The institutional framework and infrastructure for electricty production and distribution are in the process of development or still non-existent in large areas. In Indonesia the President and the Minister of Technology personally have stated their support for solar photovoltaics, but many institutional changes are still required before the Indonesian utility company can accommodate solar electricity as an integral part of its planning. In fact, the whole organization has to be adapted to the new requirements in order to develop proper pricing mechanisms, credit systems and legal frameworks. In some countries the monopolies exercised by the electricity companies prevent the market from reacting with sufficient flexibility. As in the Philippines, cooperatives could eventually be entitled to generate and sell electricity if it is produced with technologies which fit into a strategy of sustainable development.

The integral demand oriented approach must be directed to the whole rural economy. Furthermore, sectoral developments in agriculture, industry and transport have to be screened from the point of view of energy demand within the framework of sustainable development. The matching of these demands with supply policies and conversion equipment is possibly best achieved at a regional or district level. This will require special planning and implementation units within the existing planning machinery at the district level, which in some countries is already the case. An implication of this new approach is that rural energy policy is not necessarily focused on the fringe areas of the national electricity grid or on the well to do, as is often the case today.

The demand oriented approach and its related matching techniques, supported by an adequate energy pricing policy and market orientation, entail a major shift from the traditional project oriented approach. This does not mean that we are against projects. However, their function should be innovative and not primarily aimed at immediate problem solving, because individual projects can never solve rural energy problems on a large scale.

\section{CONCLUSION}

The road towards sustainable development is a complex one. For rural energy further development of appropriate institutions, attitudes and technical options is required. More analysis is needed on how to approach optimal solutions and how to balance conflicting interests. Research on the effects of pricing policies, the functioning of the market and institution building are highly relevant for developing countries. As with energy in the industrialized world, the key elements lie in policies promoting the effective management of energy demand.

'United Nations, Energy Statistics Yearbook, 1985 and 1988.

${ }^{2}$ World Committee on Environment and Development, Our Common Future (The Brundtland Report), Oxford University Press, Oxiord, UK, 1987.

${ }^{3}$ J.M.O. Surlock and D.O. Hall. Biomass, Vol 21, No 75, 1990. ${ }^{4}$ M.M. Gowen. 'Biofuel versus fossil fuel economics in developing countries: how green is the pasture?". Energy Policy. Vol 17. No 5 , October 1989.

${ }^{5} \mathrm{U}$. Hansen, Delinking of energy consumption and economic growth: the German experience', Energy Policy, Vol 18, No 7, September 1990 . 
${ }^{6} \mathrm{Op}$ cit, Ref 1.

${ }^{7}$ Ibid.

${ }^{8}$ K. Fujita, UNIDO, Vienna (data based on World Bank Atlas, World Bank, Washington, DC, 1987).

${ }^{9}$ P.J. Crutzen and M.O. Andreae, 'Biomass burning in the tropics: impact on atmospheric chemistry and biochemical cycles', Science, Vol 250, 21 December 1990.

${ }^{10} \mathrm{~A} . \mathrm{K}$. Biswas, 'Environmental concerns in Pakistan, with special reference to water and forests', Environmental Conservation, $\mathrm{Vol}$ 14, No 4, 1987.

${ }^{11} \mathrm{Op}$ cit, Ref 9.

${ }^{12}$ Described in D. Mackenzie, Energy answers for North and South', New Scientist, 18 February 1991.

${ }^{13}$ Government of the Netherlands, To Choose or to Lose: National Environmental Policy Plan, SDU, The Hague, 1989.

${ }^{14} \mathrm{C}$. Daey Ouwens, 'Half a dollar per $\mathrm{kWh}$ and still cheap electricity', paper presented to the Tenth European Photovoltaic Solar Energy Conference and Exhibition, Lisbon, April 1991.

${ }^{15}$ Commission of the European Communities and University of
Twente, Planning and Managing Energy in Rural Areas in Developing Countries, Course Manual, CEC, Brussels, 1988. ${ }^{16}$ Ministry of Foreign Affairs and University of Twente, Renewable Energy for Developing Countries: 10 Years of Dutch Experience, The Hague, 1987.

${ }^{17}$ Op cit, Ref 15.

${ }^{18} \mathrm{~J}$.C. Burgess, "The contribution of efficient energy pricing to reducing $\mathrm{CO}_{2}$ emissions', Energy Policy, Vol 18, No 5, June 1990.

${ }^{19} \mathrm{M}$. Kosmo, 'Commercial energy subsidies in developing countries: opportunity for reform', Energy Policy, Vol 17, No 3, June 1989.

${ }^{20} \mathrm{O}$. Hohmeyer, 'The full costs of electricity generation: how does photovoltaics compare today?', paper presented at the Tenth European Photovoltaic Solar Energy Conference and Exhibition, Lisbon, April 1991.

${ }^{21} \mathrm{~N}$. Jenkins, 'It is energy we need, not electricity', Energy Policy, Vol 18, No 5, June 1990.

${ }^{22}$ UNDP/ESCAP/FAO, A New Approach to Energy Planning for Sustainable Rural Development, Rome, 1990. 